\title{
Effect of parenteral selenium administration on oxidative status of weaned piglets
}

\author{
Martin Svoboda ${ }^{1}, Z_{\text {deněk Fajt }}{ }^{1}$, Jan Vašek ${ }^{1}$, Jonáš Vaňhara ${ }^{1}$, Martin Hostovský ${ }^{2}$, \\ Jana Blahová ${ }^{2}$, Aleš Franc ${ }^{3}$
}

University of Veterinary and Pharmaceutical Sciences Brno, ${ }^{1}$ Faculty of Veterinary Medicine, Ruminant and Swine Clinic, ${ }^{2}$ Faculty of Veterinary Hygiene and Ecology, Department of Animal Welfare, Protection and Behaviour, ${ }^{3}$ Faculty of Pharmacy, Department of Pharmaceutics and Biopharmacy, Brno, Czech Republic

Received September 27, 2016

Accepted December 2, 2016

\begin{abstract}
The aim of the study was to evaluate the effect of additional selenium injection after weaning on the selenium (Se) status of piglets and to find whether the selected dose would be appropriate with respect to the level of oxidative stress. Another goal was to compare the efficacy and safety of sodium selenite and selenopyran as selenium sources for parenteral administration to piglets. Altogether 30 piglets were divided equally into three groups. Piglets in group 1 were injected i.m. with sodium selenite, piglets in group 2 were injected with selenopyran. The dose was $0.42 \mathrm{mg}$ $\mathrm{Se} / \mathrm{kg}$ body weight for both groups. Piglets in group 3 were given only saline. As expected, the study revealed low Se serum concentrations in weaned piglets. The injection of sodium selenite increased Se serum concentrations but did not have a positive effect on the peroxidase activities. Administration of selenopyran did not influence Se concentrations and gluthation peroxidase activities. The selected dose did not have a significant impact on the level of the oxidative stress. The piglets receiving Se only from the feed achieved comparable gluthation peroxidase activities during the trial. It seems that despite initially low Se concentrations, the physiological requirements for gluthation peroxidase synthesis were met with the feed consumption as the only Se source. The results of the study are important because until now it was unclear whether the selected dose would have negative effects on the organism with respect to the induction of oxidative stress in piglets.
\end{abstract}

Selenopyran, swine, carbonyl groups, TBARS, antioxidant

Selenium (Se) is an essential nutrient for swine. It has important antioxidant functions primarily through the gluthation peroxidase enzyme (Sunde 1994). Its deficiency can represent a serious problem in swine production. The most common problem is the presence of the mulberry heart disease (Van Vleet et al. 1975). The deficiency is most frequently found in pigs during the first weeks post weaning (Mahan 1996). Upon weaning, a rapid decline in pig serum and tissue Se concentrations occurs (Meyer et al. 1981). Despite the high dietary concentrations of Se in starter diets, its deficiency can still be found on some farms. Sivertsen et al. (2007) found that $54 \%$ of the piglets after weaning had plasma Se concentrations below physiological levels. This raises a question whether it would be beneficial for some farms to inject pigs with $\mathrm{Se}$ at weaning. Inorganic sodium selenite and organic selenopyran are available for i.m. administration. The use of injective selenopyran could be advantageous because it has low toxicity (Boryaev and Kravchenko 2006). Selenopyran has been used recently for the improvement of the antioxidant status of pig ovaries (Abadjieva et al. 2014). Selenopyran also increased Se content in the sperm of rams (Kistanova et al. 2015).

To our knowledge, there are no objective data yet evaluating the effects of additional selenium injection to piglets after weaning on their selenium and oxidative status. The first aim of the study was to evaluate the effect of additional selenium injection after weaning on

Address for correspondence:

Doc. MVDr. Martin Svoboda, Ph.D.

Ruminant and Swine Clinic

Faculty of Veterinary Medicine

University of Veterinary and Pharmaceutical Sciences Brno

Palackého tř. 1946/1, 61242 Brno, Czech Republic 
the selenium status of piglets. The second aim was to find whether the selected dose would have an impact on the level of oxidative stress in piglets. The third aim was to compare the efficacy and safety of sodium selenite and selenopyran as Se sources for parenteral administration to piglets.

\section{Materials and Methods}

\section{Experimental design}

Altogether 30 weaned piglets were used in the study. They originated from sows of the third parity. The piglets were weaned on day 28. At weaning, the piglets were allotted to three equal groups according to the principle of split litters. Then pigs were moved to a climate-controlled facility and placed in weaning pens situated next to each other. Pigs were individually marked with a plastic badge in the right ear.

The feed of sows contained $0.3 \mathrm{mg} \mathrm{Se} / \mathrm{kg}$ in the form of sodium selenite. Starting from 10 days of age the piglets had ad libitum access to the pre-starter diet. This diet contained $0.4 \mathrm{mg} \mathrm{Se} / \mathrm{kg}$, of which $0.3 \mathrm{mg} \mathrm{Se} /$ $\mathrm{kg}$ was present as sodium selenite and $0.1 \mathrm{mg} \mathrm{Se} / \mathrm{kg}$ was in the form of selenium enriched yeast. The diet was administered till 2 weeks after weaning. Then the piglets were offered the starter diet with $0.3 \mathrm{mg} \mathrm{Se} / \mathrm{kg}$ as sodium selenite. The diets were produced by De Heus a.s., Marefy, Czech Republic.

Piglets in group 1 were injected intramuscularly with oil solution of selenopyran 10 days after weaning at a dose of $0.42 \mathrm{mg} \mathrm{Se} / \mathrm{kg}$ live weight. Selenopyran was provided by Penza State Agricultural Academy, Russia. Piglets in group 2 were injected with sodium selenite in water solution at a dose of $0.42 \mathrm{mg}$ Se/ $\mathrm{kg}$ live weight. Piglets in group 3 were injected saline and served as the control group. Brno.

The study was approved by the Ethics Committee of the University of Veterinary and Pharmaceutical Sciences

\section{Sampling and analysis}

Blood samples were taken before the injection of selenium, $48 \mathrm{~h}$ after the administration, and then 7,14 , and 21 days post treatment. The piglets were weighed at the same intervals. Blood was collected from their vena cava cranialis. After sampling, part of the blood sample was coagulated in special sterile tubes with serum accelerators for determination of Se concentrations. Heparin was used as an anticoagulant for determination of the antioxidant status and blood biochemistry.

Selenium concentrations were determined by the Solar 939 AA spectrometer (Unicam, UK) using the hydride AAS technique. The samples were prepared by mineralization in a closed system using a microwave (MLS-1200, Milestone, Italy) digestion technique with $\mathrm{HNO}_{3}$ and $\mathrm{H}_{2} \mathrm{O}_{2}$. After mineralization, the samples were evaporated and the mineral residue dissolved in water to which $20 \% \mathrm{HCl}^{2}$ was added.

Vitamin E concentrations in serum were determined fluorometrically according to Bouda et al. (1980) using fluorescence spectrophotometer 204 (Perkin-Elmer, USA).

The activity of GPx (gluthation peroxidase) in plasma was determined spectrophotometrically and calculated from the rate of nicotinamide adenine dinucleotide phosphate-oxidase (NADPH) oxidation by the reaction with gluthation reductase (GR) at $340 \mathrm{~nm}$ (Flohe and Gunzler 1984). The specific activity of was expressed as the nmol of NADPH consumption per min per mg of protein.

The concentration of thiobarbituric acid reactive substances (TBARS) in plasma was measured spectrophotometrically at $535 \mathrm{~nm}$ using the Varioskan flash spectral scanning multimode reader (Thermo Fisher Scientific Inc., USA) according to the method described by Ohkawa et al. (1979) with modifications by Lushchak et al. (2005). The TBARS concentrations are expressed as nanomoles per milliliter of plasma.

Trolox equivalent antioxidant capacity (TEAC) was determined in plasma following the protocol of Re et al. (1999) and measured spectrophotometrically at $734 \mathrm{~nm}$ using a Varioskan flash spectral scanning multimode reader (Thermo Fisher Scientific Inc., USA). The TEAC values were expressed as millimoles of trolox as external standard per milliliter of plasma.

Carbonyl derivatives of proteins (CP) were detected spectrophotometrically by reaction with 2,4-dinitrophenylhydrazine (DNPH) using the Varioskan flash spectral scanning multimode reader (Thermo Fisher Scientific Inc., USA) according to the method described by Lenz et al. (1989) and modified by Lushchak et al. (2005). The CP are quantified as nanomoles of CP per plasma protein miligram. Plasma protein concentrations in guanidine chloride solution for CP were determined by the Bicinchoninic Acid Protein Assay Kit (Sigma-Aldrich, St. Louis, MO, USA) using bovine serum albumin as a standard (Smith et al. 1985).

The ceruloplasmin activity in plasma was analysed according to Ceron and Martinez-Subiela (2004) with slight modifications using the Varioskan flash spectral scanning multimode reader (Thermo Fisher Scientific Inc., USA). Results were expressed as the amount of the absorbance increase per $\min \times 10,000$. Ferric reducing ability of plasma (FRAP) was measured on a biochemical analyzer Konelab 20i according to Benzie and Strain (1996).

The other plasma biochemical indices such as total protein (TP), alanine aminotransferase (ALT), aspartate aminotransferase (AST), alkaline phosphatase (ALP), lactate dehydrogenase (LDH-L), creatine kinase (CK), and creatinine (CREAT) were determined using the biochemical analyzer Konelab 20i and commercial kits (Biovendor, Czech Republic). 
Statistical analysis

Statistical assessment was carried out using Statistica for Windows 8.0. software (Czech Republic). Data were tested for normality (Kolmogorov-Smirnov test). Data did not satisfy normal distribution, therefore, nonparametric Kruskall-Wallis test was used to test the differences between the groups. Moreover, the data were subjected to two-way ANOVA with treatment (control, sodium selenite, and selenopyran) and day of sampling (day $0,2,7,14$ and 21) as the main effects along with their interactions. Significant differences in all possible pairs of groups were evaluated using post-hoc Tukey-HSD test. Significance was accepted at $P<0.05$. All data are reported as mean \pm standard deviation.

\section{Results}

Serum Se concentration

The results are presented in Fig. 1.

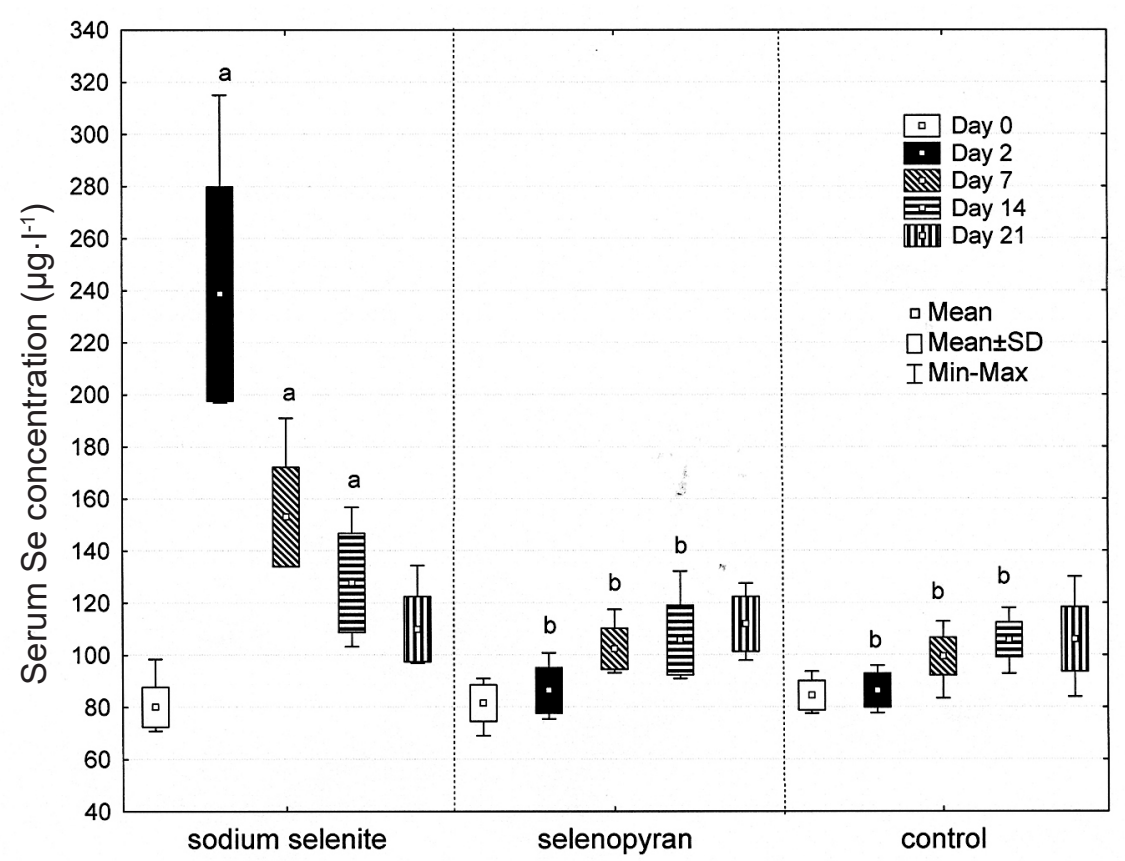

Fig. 1. Selenium concentration of weaned piglets administered different forms of selenium

The results are expressed as mean \pm standard deviation. Day 0 means the time of application. Significant differences $(P<0.05)$ between groups are indicated by different alphabetic superscript.

In the control group of our study, the mean serum selenium values appeared to increase from day 0 to day 21 , however, the differences were not significant.

Sodium selenite injection at a dose of $0.42 \mathrm{mg} \mathrm{Se} / \mathrm{kg}$ caused a significant increase of selenium serum concentrations on day 2 (two days after application). These concentrations declined thereafter but continued to be higher compared to the control group during the first two weeks after treatment.

Serum Se concentrations after the injection of selenopyran remained comparable to the control group in all the periods of the study. In contrast to the control group, there was a significant increase of serum Se in the selenopyran group from day 0 to 21 . 
Oxidative status

The results of TBARS and CP concentrations are presented in Figs 2 and 3.

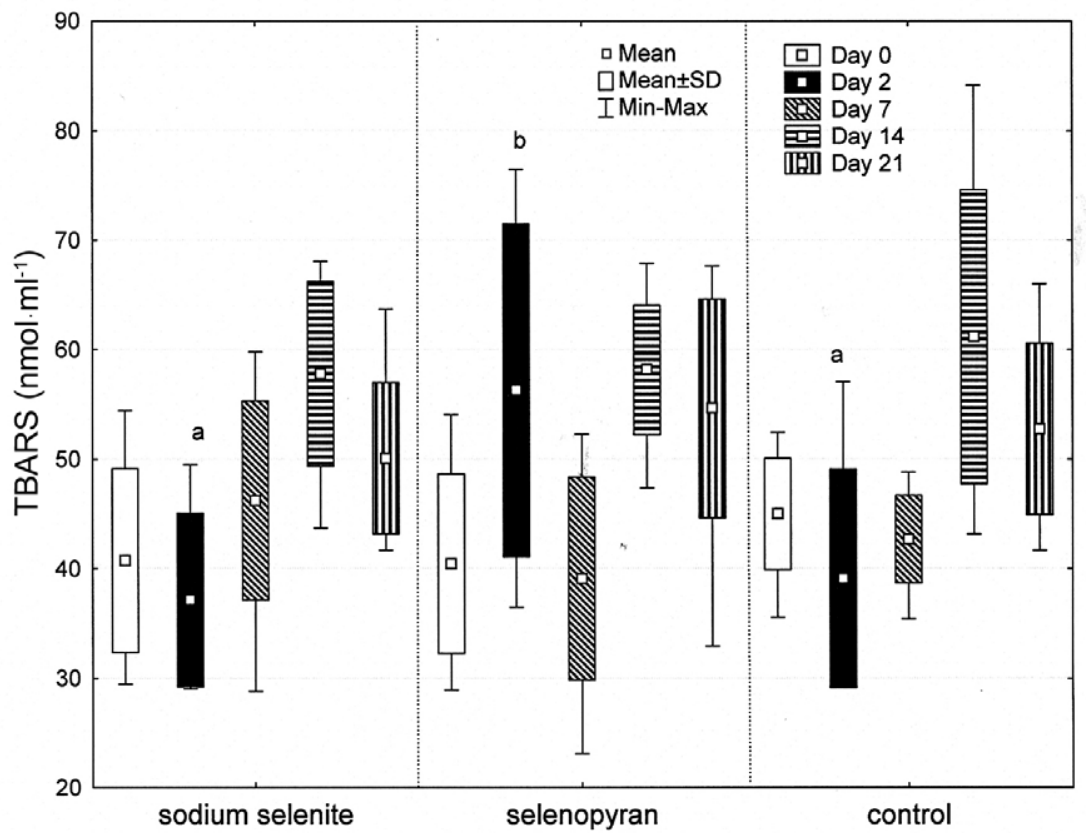

Fig. 2. Thiobarbituric acid reactive substances concentration of weaned piglets administered different forms of selenium

The results are expressed as mean \pm standard deviation. Day 0 means the time of application.

Significant differences $(P<0.05)$ between groups are indicated by different alphabetic superscript. TBARS thiobarbituric acid reactive substances

The other results (vitamin E, GPx, FRAP, TEAC, ceruloplasmin) are presented in Table 1.

In the sodium selenite group, CP concentrations were found to be higher compared to the control group on day 2. In the selenopyran group, TBARS concentrations were higher than control two days after injection. One week after treatment the values returned to normal, i.e. they were statistically comparable to the control group. There was also an increase of protein oxidation in the selenopyran group. Compared to control, the values of CP remained to be higher in all the periods of the trial. No other differences in the oxidative status were found between the groups in any period of the trial.

\section{Blood biochemistry}

The results are presented in Table 2. In the selenopyran group, LDH-L activities were lower and creatinine concentrations higher compared to control seven days after treatment. No other significant differences in the studied biochemical indices were found between the groups in any period of the trial.

\section{Body weight}

The results are presented in Table 3. No significant differences in the achieved body weights were noted between the groups in any period of the trial. 


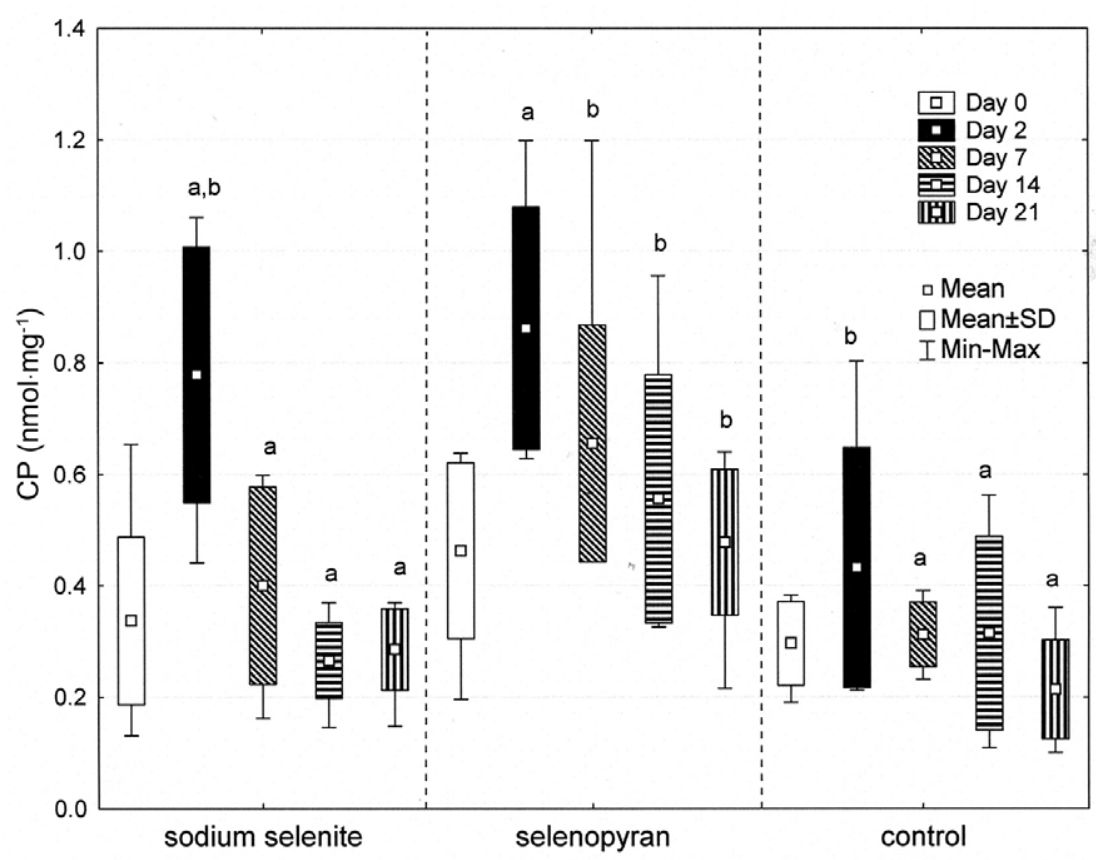

Fig. 3. Carbonyl protein concentration of weaned piglets administered different forms of selenium The results are expressed as mean \pm standard deviation. Day 0 means the time of application.

Significant differences $(P<0.05)$ between groups are indicated by different alphabetic superscript. CP - carbonyl protein

\section{Discussion}

Ullrey (1987) and Mahan (1991) declare selenium serum concentrations ranging between 80 and $150 \mu \mathrm{g} / \mathrm{l}$ as normal in pigs. Blood and Radostits (1989) stated that normal concentrations should be even higher, i.e. above $120 \mu \mathrm{g} / \mathrm{l}$ serum. Our results confirm that despite high dietary concentrations of Se in starter diets, its deficiency can still be found on some farms. Ten days after weaning, the mean Se concentrations were around $80 \mu \mathrm{g} / \mathrm{l}$. We found $33 \%$ of piglets with Se concentrations below $80 \mu \mathrm{g} / \mathrm{l}$. This is in line with the findings of Sivertsen et al. (2007) who reported plasma Se concentrations below $80 \mu \mathrm{g} / \mathrm{l}$ in $54 \%$ of weaned piglets, and concentrations of $60 \mu \mathrm{g} / \mathrm{l}$ or less in $19 \%$ of weaned piglets. In pig production, selenium is added routinely to starter diets at a concentration of $0.3-0.4 \mathrm{ppm}$ (Sivertsen et al. 2007). The reasons why serum concentrations are low after weaning despite dietary selenium supplementation could be attributed to the following facts. At weaning, a decline in pig serum and tissue Se concentrations occurs (Meyer et al. 1981). Piglets usually eat little during the first days after weaning (Bruininx et al. 2002). The low food intake predisposes them to gastrointestinal disorders and weight loss (Madec et al. 1998).

The increase of serum Se concentrations in the control group was not significant. The initial suboptimal concentrations $(20 \%$ piglets $)$ were eliminated as a Se concentration below $80 \mu \mathrm{g} / \mathrm{l}$ was not found in any piglet at the end of trial. This indicates that the deficit was supplemented from the feed. 
Table 1. Oxidative status of weaned piglets administered different forms of selenium.

\begin{tabular}{|c|c|c|c|c|c|c|}
\hline & $\begin{array}{l}\text { Study } \\
\text { day }\end{array}$ & $\begin{array}{l}\text { Vitamin E } \\
{[\mu \mathrm{mol} / 1]}\end{array}$ & $\begin{array}{c}\mathrm{GSH}-\mathrm{PX} \\
{[\mathrm{nmol}} \\
\mathrm{NADPH} / \mathrm{min} / \mathrm{ml}]\end{array}$ & $\begin{array}{c}\text { FRAP } \\
{[\mu \mathrm{mol} / 1]}\end{array}$ & $\begin{array}{c}\text { TEAC } \\
{[\mu \mathrm{M} / \mathrm{ml}]}\end{array}$ & $\begin{array}{l}\text { Ceruloplasmin } \\
{\left[\Delta \mathrm{A} / \mathrm{min} \times 10^{4}\right]}\end{array}$ \\
\hline \multirow{15}{*}{$\begin{array}{l}\text { Sodium } \\
\text { selenite }\end{array}$} & \multirow[t]{3}{*}{0} & 2.42 & 577.45 & 201.92 & 0.66 & 370.26 \\
\hline & & $+/-$ & $+/-$ & $+/-$ & $+/-$ & $+/-$ \\
\hline & & 0.58 & 190.54 & 36.20 & 0.08 & 163.30 \\
\hline & \multirow[t]{3}{*}{2} & 2.27 & 450.13 & 224.37 & 0.69 & 288.04 \\
\hline & & $+/-$ & $+/-$ & $+/-$ & $+/-$ & $+/-$ \\
\hline & & 0.95 & 121.47 & 28.98 & 0.14 & 100.46 \\
\hline & \multirow[t]{3}{*}{7} & 3.01 & 476.30 & 268.35 & 0.72 & 293.85 \\
\hline & & 0.71 & $+/-$ & $+/-$ & $+/-$ & $+/-$ \\
\hline & & & 103.47 & 33.77 & 0.16 & 133.14 \\
\hline & \multirow[t]{3}{*}{14} & 3.08 & 545.74 & 282.94 & 0.86 & 292.33 \\
\hline & & $+/-$ & $+/-$ & $+/-$ & $+/-$ & $+/-$ \\
\hline & & 0.95 & 79.22 & 35.14 & 0.07 & 86.29 \\
\hline & \multirow[t]{3}{*}{21} & 2.55 & 642.01 & 212.76 & 0.73 & 271.11 \\
\hline & & $+/-$ & $+/-$ & $+/-$ & $+/-$ & $+/-$ \\
\hline & & 0.48 & 86.77 & 26.12 & 0.09 & 65.30 \\
\hline \multirow[t]{15}{*}{ Selenopyran } & \multirow[t]{3}{*}{0} & 2.43 & 557.87 & 218.95 & 0.61 & 440.73 \\
\hline & & $+/-$ & $+/-$ & $+/-$ & $+/-$ & $+/-$ \\
\hline & & 0.58 & 105.73 & 19.62 & 0.12 & 129.71 \\
\hline & \multirow[t]{3}{*}{2} & 2.73 & 496.04 & 243.01 & 0.67 & 396.57 \\
\hline & & $+/-$ & $+/-$ & $+/-$ & $+/-$ & $+/-$ \\
\hline & & 0.51 & 82.54 & 28.17 & 0.17 & 109.87 \\
\hline & \multirow[t]{3}{*}{7} & 3.47 & 472.41 & 272.69 & 0.64 & 288.80 \\
\hline & & $+/-$ & $+/-$ & +/- & $+/-$ & $+/-$ \\
\hline & & 0.75 & 91.64 & 33.66 & 0.19 & 86.46 \\
\hline & \multirow[t]{3}{*}{14} & 3.28 & 539.14 & 273.47 & 0.81 & 325.33 \\
\hline & & $+/-$ & $+/-$ & $+/-$ & $+/-$ & $+/-$ \\
\hline & & 0.68 & 58.66 & 34.06 & 0.07 & 84.42 \\
\hline & \multirow[t]{3}{*}{21} & 2.99 & 616.26 & 222.74 & 0.70 & 303.47 \\
\hline & & $+/-$ & $+/-$ & $+/-$ & $+/-$ & $+/-$ \\
\hline & & 0.86 & 83.88 & 31.64 & 0.08 & 118.86 \\
\hline \multirow[t]{15}{*}{ Control } & \multirow[t]{3}{*}{0} & 2.18 & 596.22 & 225.74 & 0.66 & 336.47 \\
\hline & & $+/-$ & +/- & $+/-$ & $+/-$ & $+/-$ \\
\hline & & 0.61 & 107.77 & 35.41 & 0.12 & 84.89 \\
\hline & \multirow[t]{3}{*}{2} & 2.75 & 465.08 & 243.61 & 0.67 & 377.63 \\
\hline & & $+/-$ & $+/-$ & $+/-$ & $+/-$ & $+/-$ \\
\hline & & 0.84 & 62.76 & 34.07 & 0.11 & 104.68 \\
\hline & \multirow[t]{3}{*}{7} & 3.03 & 477.49 & 279.71 & 0.72 & 261.44 \\
\hline & & $+/-$ & $+/-$ & $+/-$ & $+/-$ & $+/-$ \\
\hline & & 0.90 & 66.86 & 54.85 & 0.11 & 70.02 \\
\hline & \multirow[t]{3}{*}{14} & 3.37 & 577.14 & 285.94 & 0.85 & 298.53 \\
\hline & & $+/-$ & $+/-$ & $+/-$ & $+/-$ & $+/-$ \\
\hline & & 0.81 & 84.93 & 44.08 & 0.07 & 55.06 \\
\hline & \multirow[t]{3}{*}{21} & 2.93 & 721.34 & 219.05 & 0.70 & 265.33 \\
\hline & & $+/-$ & +/- & $+/-$ & $+/-$ & $+/-$ \\
\hline & & 0.55 & 139.82 & 38.56 & 0.04 & 70.01 \\
\hline
\end{tabular}

The results are expressed as mean \pm standard deviation. Day 0 means the time of application.

FRAP- ferric reducing ability of plasma, GPx-gluthation peroxidase, TEAC-trolox equivalent antioxidant capacity. 
Table 2. Blood biochemistry of weaned piglets administered different forms of selenium.

\begin{tabular}{|c|c|c|c|c|c|c|c|c|c|}
\hline & $\begin{array}{l}\text { Study } \\
\text { day }\end{array}$ & $\begin{array}{c}\mathrm{TP} \\
{[\mathrm{g} / \mathrm{l}]}\end{array}$ & $\begin{array}{c}\text { ALT } \\
{[\mu \mathrm{kat} / 1]}\end{array}$ & $\begin{array}{c}\text { AST } \\
{[\mu \mathrm{kat} / 1]}\end{array}$ & $\begin{array}{c}\text { ALP } \\
{[\mu \mathrm{kat} / 1]}\end{array}$ & $\begin{array}{l}\text { LDH- L } \\
{[\mu \mathrm{kat} / \mathrm{l}]}\end{array}$ & $\begin{array}{c}\mathrm{CK} \\
{[\mu \mathrm{kat} / \mathrm{l}]}\end{array}$ & $\begin{array}{c}\text { Urea } \\
{[\mathrm{mmol} / \mathrm{l}]}\end{array}$ & $\begin{array}{l}\text { CREAT } \\
{[\mu \mathrm{mol} / 1]}\end{array}$ \\
\hline \multirow{15}{*}{$\begin{array}{l}\text { Sodium } \\
\text { selenite }\end{array}$} & \multirow[t]{3}{*}{0} & 45.33 & 0.90 & 0.70 & 14.02 & 14.02 & 7.83 & 1.26 & 102.54 \\
\hline & & $+/-$ & $+/-$ & $+/-$ & $+/-$ & $+/-$ & $+/-$ & $+/-$ & $+/-$ \\
\hline & & 3.08 & 0.12 & 0.14 & 7.28 & 1.77 & 2.09 & 0.59 & 22.85 \\
\hline & \multirow[t]{3}{*}{2} & 43.20 & 1.10 & 0.91 & 14.02 & 14.47 & 11.79 & 0.86 & 87.30 \\
\hline & & $+/-$ & $+/-$ & $+/-$ & $+/-$ & $+/-$ & $+/-$ & $+/-$ & $+/-$ \\
\hline & & 5.59 & 0.15 & 0.24 & 7.60 & 2.02 & 6.19 & 0.29 & 17.01 \\
\hline & \multirow[t]{3}{*}{7} & 46.71 & 1.32 & 1.03 & 14.68 & 16.40 & 15.26 & 1.32 & 91.30 \\
\hline & & $+/-$ & $+/-$ & $+/-$ & $+/-$ & $+/-$ & $+/-$ & $+/-$ & $+/-$ \\
\hline & & 10.67 & 0.56 & 0.17 & 7.15 & 2.86 & 5.28 & 0.91 & 18.44 \\
\hline & \multirow[t]{3}{*}{14} & 48.65 & 1.82 & 1.27 & 6.83 & 15.64 & 15.86 & 1.62 & 96.88 \\
\hline & & $+/-$ & $+/-$ & $+/-$ & $+/-$ & $+/-$ & $+/-$ & $+/-$ & $+/-$ \\
\hline & & 5.12 & 0.44 & 0.15 & 5.50 & 2.73 & 4.48 & 0.82 & 11.14 \\
\hline & \multirow[t]{3}{*}{21} & 53.07 & 1.93 & 1.01 & 12.66 & 13.85 & 25.44 & 2.21 & 92.85 \\
\hline & & $+/-$ & $+/-$ & $+/-$ & $+/-$ & $+/-$ & $+/-$ & $+/-$ & $+/-$ \\
\hline & & 5.31 & 0.63 & 0.17 & 5.70 & 2.29 & 21.00 & 1.04 & 15.69 \\
\hline \multirow[t]{15}{*}{ Selenopyran } & \multirow[t]{3}{*}{ n 0} & 45.74 & 0.81 & 0.85 & 8.06 & 14.26 & 7.03 & 1.12 & 102.99 \\
\hline & & $+/-$ & $+/-$ & $+/-$ & $+/-$ & $+/-$ & $+/-$ & $+/-$ & $+/-$ \\
\hline & & 5.53 & 0.12 & 0.23 & 1.94 & 3.73 & 2.65 & 0.60 & 7.64 \\
\hline & \multirow[t]{3}{*}{2} & 42.99 & 1.11 & 0.90 & 12.99 & 14.12 & 11.80 & 1.35 & 83.96 \\
\hline & & $+/-$ & $+/-$ & $+/-$ & $+/-$ & $+/-$ & $+/-$ & $+/-$ & $+/-$ \\
\hline & & 2.44 & 0.21 & 0.19 & 3.72 & 2.71 & 6.70 & 0.80 & 10.31 \\
\hline & \multirow[t]{3}{*}{7} & 49.05 & 1.81 & 1.15 & 9.08 & 13.42 & 18.15 & 1.27 & 107.39 \\
\hline & & $+/-$ & $+/-$ & $+/-$ & $+/-$ & $+/-$ & $+/-$ & $+/-$ & $+/-$ \\
\hline & & 5.16 & 0.52 & 0.43 & 3.63 & $4.22^{\mathrm{a}}$ & 12.47 & 0.34 & $17.80^{\mathrm{a}}$ \\
\hline & \multirow[t]{3}{*}{14} & 48.44 & 1.85 & 1.31 & 9.90 & 16.88 & 14.89 & 1.76 & 108.41 \\
\hline & & $+/-$ & $+/-$ & $+/-$ & $+/-$ & $+/-$ & $+/-$ & $+/-$ & $+/-$ \\
\hline & & 3.51 & 0.45 & 0.40 & 3.66 & 4.11 & 6.03 & 0.48 & 9.42 \\
\hline & \multirow[t]{3}{*}{21} & 53.97 & 1.94 & 0.95 & 21.65 & 14.67 & 30.95 & 2.41 & 100.26 \\
\hline & & $+/-$ & $+/-$ & $+/-$ & $+/-$ & $+/-$ & $+/-$ & $+/-$ & $+/-$ \\
\hline & & 4.10 & 0.62 & 0.24 & 7.03 & 2.50 & 27.59 & 0.25 & 9.52 \\
\hline \multirow[t]{15}{*}{ Control } & \multirow[t]{3}{*}{0} & 47.03 & 0.91 & 0.73 & 8.09 & 13.42 & 7.29 & 1.29 & 102.97 \\
\hline & & $+/-$ & $+/-$ & $+/-$ & $+/-$ & $+/-$ & $+/-$ & $+/-$ & $+/-$ \\
\hline & & 6.11 & 0.21 & 0.15 & 3.33 & 2.23 & 2.87 & 0.57 & 15.68 \\
\hline & \multirow[t]{3}{*}{2} & 45.68 & 1.04 & 0.93 & 11.59 & 14.04 & 10.66 & 1.23 & 88.78 \\
\hline & & $+/-$ & $+/-$ & $+/-$ & $+/-$ & $+/-$ & $+/-$ & $+/-$ & $+/-$ \\
\hline & & 3.45 & 0.25 & 0.23 & 5.57 & 1.74 & 3.03 & 0.57 & 14.73 \\
\hline & \multirow[t]{3}{*}{7} & 47.28 & 1.73 & 1.36 & 10.12 & 17.62 & 20.26 & 1.05 & 86.91 \\
\hline & & $+/-$ & $+/-$ & $+/-$ & $+/-$ & $+/-$ & $+/-$ & $+/-$ & $+/-$ \\
\hline & & 4.13 & 0.54 & 0.33 & 5.27 & $2.42^{\mathrm{b}}$ & 7.74 & 0.23 & $5.47^{\mathrm{b}}$ \\
\hline & \multirow[t]{3}{*}{14} & 49.80 & 2.46 & 1.40 & 10.27 & 15.60 & 14.65 & 1.894 & 105.77 \\
\hline & & $+/-$ & $+/-$ & $+/-$ & $+/-$ & $+/-$ & $+/-$ & $+/-$ & $+/-$ \\
\hline & & 3.97 & 0.92 & 0.41 & 4.39 & 2.59 & 5.80 & 0.5 & 16.04 \\
\hline & \multirow[t]{3}{*}{21} & 52.92 & 2.60 & 1.17 & 15.60 & 11.94 & 30.69 & 2.13 & 94.52 \\
\hline & & $+/-$ & $+/-$ & $+/-$ & $+/-$ & $+/-$ & $+/-$ & $+/-$ & $+/-$ \\
\hline & & 3.89 & 1.06 & 0.49 & 9.46 & 5.51 & 23.81 & 0.76 & 8.72 \\
\hline
\end{tabular}

The results are expressed as mean \pm standard deviation. Day 0 means the time of application. Significant differences $(P<0.05)$ between groups are indicated by different alphabetic superscript. ALP - alkaline phosphatase, ALT - alanine aminotransferase, AST - aspartate aminotransferase, CK - creatine kinase, CREAT - creatinine, LDH-L - lactate dehydrogenase, TP - Total protein. 
Table 3. Body weight $(\mathrm{kg})$ of weaned piglets administered different forms of selenium.

\begin{tabular}{|c|c|c|c|}
\hline \multicolumn{4}{|c|}{ Weight [kg] } \\
\hline Study day & Sodium selenite & Selenopyran & Control \\
\hline \multirow[t]{3}{*}{0} & 9.8 & 9.6 & 9.7 \\
\hline & $+/-$ & $+/-$ & $+/-$ \\
\hline & 2.2 & 1.6 & 2.1 \\
\hline \multirow[t]{3}{*}{7} & 11.9 & 12.4 & 12.6 \\
\hline & $+/-$ & $+/-$ & $+/-$ \\
\hline & 2.7 & 2.1 & 2.7 \\
\hline \multirow[t]{3}{*}{14} & 14.5 & 14.3 & 14.9 \\
\hline & $+/-$ & $+/-$ & $+/-$ \\
\hline & 2.9 & 2.3 & 3.3 \\
\hline \multirow[t]{3}{*}{21} & 19.0 & 18.9 & 19.5 \\
\hline & $+/-$ & $+/-$ & $+/-$ \\
\hline & 3.7 & 3.1 & 3.7 \\
\hline
\end{tabular}

The results are expressed as mean \pm standard deviation. Day 0 means the time of application.

In our study, sodium selenite injection at a dose of $0.42 \mathrm{mg} \mathrm{Se} / \mathrm{kg}$ caused a significant increase of serum Se concentrations two days after treatment. These concentrations declined thereafter but remained to be higher compared to the control group during the first two weeks after treatment. This indicates a rapid utilization of Se from this inorganic source.

Serum Se after the injection of selenopyran was comparable to the control group in all the periods. This indicates a slower utilization of Se from this source. Selenopyran is soluble in oils but not in water and hence has a longer retention time, thus serving as a kind of "Se depot" in the organism, releasing Se slowly based on the needs of the organism. Selenopyran is supposed to be transferred as a constituent part of lipoproteins (Boryaev et al. 2006). In general, when a lipid emulsion is given intramuscularly it is not transported directly to the blood. The majority of LE droplets enter the lymphatic system and eventually the blood circulation where they are taken up rapidly by the circulating monocytes for clearance by the reticuloendothelial cells (through organs such as the liver, spleen and bone marrow) (Tamilvavan 2004). All these factors could have contributed to the low serum selenium concentrations after selopyran treatment under the conditions of our study.

The TBARS are well-known secondary products of lipoperoxidation (Tsaknis et al. 1998). One day after selenopyran administration there was a transitory increase of TBARS concentration which indicates lipid peroxidation. One week after treatment the values returned to normal. There was also an increase of protein oxidation in the selenopyran group. The values of $\mathrm{CP}$ were higher in all the periods of the trial. Whereas oxidized proteins are degraded within hours or days, secondary products of lipid peroxidation are detoxified generally within minutes (Grune et al. 1995; Siems et al. 1997; Dalle-Donne et al. 2003). In our study, there was a slight increase in oxidative stress after selenopyran administration but the products of lipid peroxidation are likely to be quickly removed. Oxidation products of proteins are relatively stable and remained elevated for the rest of the experiment.

The sodium selenite injection in our study caused an increase of serum Se concentrations but did not affect GPx activities compared to the control group of piglets. It has been documented that serum GPx activities reach a plateau as the dietary Se concentration rises 
with a minimal increase at higher supplemental Se concentrations (Mahan et al. 1999). Apparently, despite the fact that Se concentrations were initially low they still met the physiological requirements for Gpx synthesis under the conditions of our study.

The selected dose of $0.42 \mathrm{mg}$ Se per $\mathrm{kg}$ was not a random choice. It was based on previous studies of other authors (Van Fleet et al. 1974, 1975). These researchers found that after sodium selenite injection, toxicity and deaths occur in pigs when the dose exceeds $0.9 \mathrm{mg}$ $\mathrm{Se} / \mathrm{kg}$ body weight. Lower dosage within the range of $0.44-0.73 \mathrm{mg} \mathrm{Se} / \mathrm{kg}$ body weight does not cause death. However, they found a significant increase of plasma glutamate oxaloacetate transaminase (GOT) and creatine kinase (CK) activities when the dose of $0.72 \mathrm{mg} \mathrm{Se} / \mathrm{kg}$ body weight was given. It was probably related to the presence of skeletal myodegeneration. The effect of the lower dose $(0.44 \mathrm{mg} \mathrm{Se} / \mathrm{kg}$ body weight) on plasma enzymes was not tested in their study. Also, modern indices that are now available for the evaluation of oxidative stress were not considered in the respective studies.

Therefore, it remains unclear whether the dose of $0.42 \mathrm{mg} \mathrm{Se} / \mathrm{kg}$ that we used in our study would have any negative effects on the piglet organism with respect to the induction of oxidative stress.

Sodium selenite is a compound with a prooxidative potential (Spallholz 1994). The use of high dietary concentration of sodium selenite in our study did not result in increased lipid oxidation and did not influence negatively other biochemical indices. This can be explained by the fact that Se from sodium selenite builds up in tissues only up to physiological levels, with any excess being excreted in urine (Lindberg and Lannek 1965).

It can be concluded that the additional injection of sodium selenite after weaning increased serum Se concentrations but did not have any positive effect on the GPx activities. Administration of selenopyran did not influence Se concentrations or GPx activities.

The selected dose of 0.42 Se can be regarded as safe because it did not have a significant impact on the level of the oxidative stress and other biochemical indices.

The piglets that were receiving Se only from the feed achieved comparable GPx activities during all the periods of the trial. Apparently, despite the fact that the Se concentrations were initially low, the physiological requirements for GPx synthesis could be met with the use of Se from the feed as the only source.

\section{Acknowledgement}

This research was supported by the Internal Grant Agency 123/2015/FVL, University of Veterinary and Pharmaceutical Sciences Brno, Czech Republic.

\section{References}

Abadjieva VD, Kistanova E, Maechev Y, Nedeva R, Vaisberg C, Stefanov RG, Boryaev G, Nevitov M 2014: Improvement of the antioxidative status of pig ovaries by selenopyran treatment. Mac Vet Rev 37: 165-170

Benzie IFF, Strain JJ 1996: The ferric reducing ability of plasma (FRAP) as a measure of "antioxidant power": The FRAP assay. Anal Biochem 239: 70-76

Blood DC, Radostits OM 1989: Veterinary Medicine: A textbook of the diseases of cattle, sheep, pigs, goats and horses. Bailliere Tindall; London, 1195 p.

Bouda J, Jagoš P, Dvořák V 1980: Fluorometric determination of vitamins A and E in blood plasma, colostrum and the liver of cattle (in Czech). Cs Fysiol 29: 351

Boryaev GI, Kravchenko Y V 2006: Selenopyran is organic compound of selenium with original biological properties. International congress Euromedica, Hannover, Germany, p. 15

Bruininx EMAM, Binnendijk GP, van der Peet-Schwering CMC, Schrama JW, den Hartog LA, Everts H, Beynen AC 2002: Effect of creep feed consumption on individual feed intake characteristics and performance of grouphoused weanling pigs. J Anim Sci 80: 1413-1418

Ceron JJ, Martinez-Subiela S 2004: An automated spectrophotometric method for measuring canine ceruloplasmin in serum. Vet Res 35: 671-679

Dalle-Donne I, Rossi R, Giustarini D, Milzani A, Colombo R 2003: Protein carbonyl groups as biomarkers of oxidative stress. Clin Chim Acta 329: 23-38

Flohe L, Gunzler WA 1984: Assays of glutathione peroxidase. Methods Enzymol 105: 114-121 
Grune T, Reinheckel T, Joshi M, Davies KJA 1995: Proteolysis in cultured liver epithelial cells during oxidative stress-role of the multicatalytic proteinase complex, proteasome. J Biol Chem 270: 2344 -2351

Kistanova E, Metodiev N, Raycheva E, Abadjieva D, Stefanov R, Mladenova V, Blazhev B, Nevitov M, Boryaev G 2015: The effect of injective application of selenopyran on the prolonged increase of the selenium content in blood and sperm of rams. Biotechnol Animal Husb 31: 481-489

Lenz AG, Costabel U, Shaltiel S, Levine RL 1989: Determination of carbonyl groups in oxidatively modified of proteins by reduction with tritiated sodium borohydride. Anal Biochem 177: 419-425

Lindberg P, Lannek N 1965: Retention of selenium in kidneys, liver and striated muscle after prolonged feeding of therapeutic amounts of sodium selenite to pigs. Acta Vet Scand 6: 217-223

Lushchak VI, Bagnyukova TV, Lushchak OV, Storey JM, Storey KB 2005: Hypoxia and recovery perturb free radical processes and antioxidant potential in common carp (Cyprinus carpio) tissues. Int J Biochem Cell Biol 37: 1319-1330

Madec F, Bridoux N, Bounaix S, Jestin A 1998: Measurement of digestive disorders in the piglet at weaning and related risk factors. Prev Vet Med 35: 53-72

Mahan DC 1991: Vitamin E and selenium in swine nutrition. In: Miller ER, Ullrey DE, Lewis AI (Eds): Swine Nutrition. Butterworth-Heinemann, Boston, pp 193-213

Mahan DC 1996: Are we still having vitamin E and selenium deficiencies in pigs? In: Illini PorkNet Papers, The Online Resource for the Pork Industry, 1-21

Mahan DC, Clone TR, Richert B 1999: Effects of dietary levels of selenium-enriched yeast and sodium selenite as selenium sources fed to growing-finishing pigs on performance, tissue selenium, serum glutathione peroxidase activity, carcass characteristics, and loin quality. J Anim Sci 77: 2172-2179

Meyer WR, Mahan DC, Moxon AL 1981: Value of dietary selenium and vitamin E for weanling swine as measured by performance and tissue selenium and glutathione peroxidase activities. J Anim Sci 52: 302-311

Ohkawa H, Ohishi N, Yagi K 1979: Assay for lipid peroxides in animal-tissues by thiobarbituric acid reaction. Anal Biochem 95: 351-358

Re R, Pellegrini N, Proteggente A, Pannala A, Yang M, Rice-Evans C 1999: Antioxidant activity applying an improved ABTS radical cation decolorization assay. Free Radic Biol Med 26: 1231-1237

Siems WG, Zollner H, Grune T, Esterbauer H 1997: Metabolic fate of 4-hydroxynonenal in hepatocytes: 1,4-dihydroxynonene is not the main product. J Lipid Res 38: 612- 622

Sivertsen T, Vie E, Bernhoft A, Baustad B 2007: Vitamin E and selenium plasma concentrations in weaning pigs under field conditions in Norwegian pig herds. Acta Vet Scand 49: 1-9

Smith PK, Krohn RI, Hermanson GT, Mallia AK, Gartner FH, Provenzano MD, Fujimoto EK, Goeke NM, Olson BJ, Klenk DC 1985: Measurement of protein using bicinchoninic acid. Anal Bioch 150: 76-85

Spallholz JE 1994: On the nature of selenium toxicity and carcinostatic activity. Free Radic Biol Med 17: 45-64

Sunde RA 1994: Intracellular glutathione peroxidases — Structure, regulation and function. In: Burk RF (Ed.), Selenium in Biology and Human Health. Springer Verlag, New York, pp. 45-77

Tamilvanan S 2004: Oil-in-water lipid emulsions: implications for parenteral and ocular delivering systems. Prog Lipid Res 43: 489-533

Tsaknis J, Stavros L, Michael H, Gillian S, Vassiliki T 1998: Rapid high-performance liquid chromatographic method of determining malondialdehyde for evaluation of rancidity in edible oils. Analyst 123: 325-327

Ullrey DE 1987: Biochemical and physiological indicators of selenium status in animals. J Anim Sci 65: $1712-1726$

Van Vleet JF, Meyer KB, Olander HJ 1974: Acute selenium toxicosis induced in baby pigs by parenteral administration of selenium-vitamin E preparations. J Am Vet Med Assoc 165: 543-547

Van Vleet JF, Meyer KB, Olander HJ, Ruth GR 1975: Efficacy and safety of Selenium-Vitamin E injections in newborn pigs to prevent subclinical deficiency in growing swine. Am J Vet Res 36: 387-393 